\title{
Effects of manipulating slowpoke calcium-dependent potassium channel expression on rhythmic locomotor activity in Drosophila larvae
}

Rhythmic motor behaviors are generated by networks of neurons. The sequence and timing of muscle contractions depends on both synaptic connections between neurons and the neurons' intrinsic properties. In particular, motor neuron ion currents may contribute significantly to motor output. Large

conductance $\mathrm{Ca}^{2+}$-dependent $\mathrm{K}^{+}(\mathrm{BK})$ currents play a role in action potential repolarization, interspike interval, repetitive and burst firing, burst termination and interburst interval in neurons. Mutations in slowpoke (slo) genes encoding BK channels result in motor disturbances. This study examined the effects of manipulating slo channel expression on rhythmic motor activity using Drosophila larva as a model system. Dual intracellular recordings from adjacent body wall muscles were made during spontaneous crawling-related activity in larvae expressing a slo mutation or a slo RNA interference construct. The incidence and duration of rhythmic activity in slo mutants were similar to wild-type control animals, while the timing of the motor pattern was altered. slo mutants showed decreased burst durations, cycle durations, and quiescence intervals, and increased duty cycles, relative to wild-type. Expressing slo RNAi in identified motor neurons phenocopied many of the effects observed in the mutant, including decreases in quiescence interval and cycle duration. Overall, these results show that altering slo expression in the whole larva, and specifically in motor neurons, changes the frequency of crawling activity. These results suggest an important role for motor neuron intrinsic properties in shaping the timing of motor output. 
McKiernan • Slowpoke channels and locomotor activity

\author{
Erin C. McKiernan ${ }^{1 *}$ \\ ${ }^{1}$ Instituto Tecnológico y de Estudios Superiores de Monterrey, Xochitepec, Morelos, México \\ ${ }^{*}$ Correspondence: emck31@gmail.com
}

\section{Introduction}

Rhythmic motor behaviors, such as respiration and locomotion, are vital to animal survival, and must be reliably and precisely controlled by the nervous system. The sequence and timing of muscle contractions producing these behaviors comprise the motor pattern, and are generated by collections of synaptically connected neurons called central pattern generating $(\mathrm{CPG})$ networks $[26,31,48]$. In many systems, motor neurons (MNs) are not part of the classically-defined CPG network [48]. However, intrinsic MN properties, such as specific ionic currents, may play a crucial role in producing proper motor output $[12,25,38,76]$ (for reviews see $[30,33,39,49]$ ). To what extent MN currents shape the motor pattern, and exactly how aspects of the pattern are altered by expression of specific ion channel genes, are open questions.

MNs display a variety of $\mathrm{K}^{+}$currents that shape responsiveness to synaptic inputs and firing output $[30,51]$. Of particular interest are $\mathrm{Ca}^{2+}$-dependent $\mathrm{K}^{+}$currents $\left(I_{K C a}\right)$ carried through 'maxi-K' or 'Big $\mathrm{K}^{\prime}$ (BK) channels $[18,60]$. BK channels require an increase in cytosolic $\mathrm{Ca}^{2+}$ and membrane depolarization to maximally activate. BK currents have been shown to play a role in action potential repolarization $[5,45,64]$, fast afterhyperpolarization $[28,61,64]$, regulation of firing frequency and interspike interval $[28,68,75]$, repetitive and burst firing $[5,28,71]$, interburst interval [75], and burst termination $[45,68,75]$. In addition, mutations in slowpoke (slo) genes encoding BK channels are associated with motor disturbances and disorders [14,53,61].

The slo gene was originally cloned in Drosophila $[3,16,65]$. Channels encoded by the slo gene carry transient $I_{K C a}$ in muscles [16,40,65], and both transient and sustained $I_{K C a}$ in neurons [59]. slo mutations in Drosophila cause action potential broad- ening $[1,7,15,16,59]$, decreased delay to first spike $[15,16]$, increased interspike interval [15], changes in firing patterns that include "abnormal regenerative responses" $[59,66]$, delayed repolarization of the neuromuscular junction [23], and reduced synaptic transmission [43,73]. Locomotor deficits are observed in adult slo mutants, including shaking under ether anesthesia, reduced flight, semi-paralysis in response to heat or bright light $[1,2,16]$, and abnormal circadian patterns of activity $[10,20]$. The role of slo channels in Drosophila MNs and their specific contribution to the timing of larval locomotor activity has not, to the author's knowledge, been reported.

This study examined the effects of manipulating slo expression on rhythmic locomotor activity in Drosophila larvae. Dual intracellular recordings were made from neighboring body wall muscles during spontaneous fictive crawling. slo expression was manipulated at two levels: (1) in the whole animal with a hypomorphic mutation, or (2) in identified MNs with a RNA interference (RNAi) construct. Overall, the results show that altering slo channel expression, either in the whole animal or in identified MNs, changes the frequency of crawling activity. In particular, these results suggest that MN intrinsic properties may shape the timing of locomotor behavior.

\section{Methods}

\section{Fly lines and rearing}

Drosophila melanogaster were reared at $25^{\circ} \mathrm{C}$ under a 12 hour light-dark cycle on standard yeastsugar-cornmeal media. Wandering third-instar larvae were used for all experiments. $\mathrm{w}^{1118}$ larvae were used as wild-type (WT) control. The slo mutant line, $s t^{1} s l^{1}$ (hereafter referred to as $s l o^{1}$ ), was obtained from Bloomington Drosophila Stock Center 
McKiernan • Slowpoke channels and locomotor activity

(Stock No. 4587). The UAS-slo RNAi line was obtained from Vienna Drosophila RNAi Center (Transformant ID: 6723). Expression of RNAi was restricted using the RRA-GAL4 driver [22] to two identified MNs: (1) the MN innervating muscle 1 with big terminal boutons of Type I (glutamatergic), known as MN1-Ib, and (2) the MN innervating dorsal muscles, including muscle 1 , via the intersegmental nerve (ISN) with small Type I terminal boutons, known as MNISN-Is [34]. MN1-Ib and MNISNIs are also known by their embryonic identities as aCC and RP2, respectively [22]. The RRA-GAL4 driver line (obtained from Subhashini Srinivasan) included a Dicer construct (UAS-Dicer/Cyo;RRAGAL4, UAS-cd8 GFP/RRA-GAL4) to increase the strength of the RNAi [13].

\section{Larval preparations}

Larvae were dissected and recorded in HL3.1 saline [19] containing (in mM): $70 \mathrm{NaCl}, 5 \mathrm{KCl}, 1.5 \mathrm{CaCl}_{2}$, $4 \mathrm{MgCl}_{2}, 10 \mathrm{NaHCO}_{3}, 5$ Trehalose, 115 Sucrose, 5 HEPES, pH 7.1-7.3. All chemicals were obtained from Sigma (St. Louis, Missouri). Previous electrophysiological studies of Drosophila larvae have used a dissection method which involves cutting up the dorsal midline $[4,9,11,21,67,69]$. However, since reliable access to intact dorsal-most body wall muscles 1 and 2 [34] was required for experiments, a new dissection method was developed in which these muscles did not risk damage from cutting down the midline or pinning. Larvae were pinned at the head and tail in silicone elastomer (Sylgard)-lined dishes. A cut was made to the right of the dorsal midline, typically through muscle 4 [34], which left all muscles and axons on one side of the larva intact for recording. The opposite side suffered damage to the muscles through which the cut was made. In addition, the peripheral nerves which lie in the muscle field were cut as a result of the incision, leaving many of the muscles in the dorsal group on the cut side without functional innervation. All organs and fat bodies were removed to allow access to the muscles. Larvae dissected with this method generated rhythmic peristaltic waves similar to those recorded from larvae dissected up the midline, except for an acceleration of the rhythm (see Supplemental Materials 1). This new larval preparation is referred to herein as the 'off-midline dissection' (Fig. 1).

\section{Electrophysiology}

Intracellular recordings were made at room temperature $\left(21-23^{\circ} \mathrm{C}\right)$ from dorsal muscles 1 or 2 in abdominal segments $2-6$, as described previously by others $[4,9]$. In the majority of experiments, muscles in two adjacent segments were simultaneously recorded, while in a few experiments muscle activity from only one segment was recorded. Sharp electrodes were pulled from thin-walled borosilicate glass on a P-87 Flaming/Brown filament puller (Sutter Instrument Co.) to a resistance of 30-50 $\mathrm{M} \Omega$. Using a long and flexible tip was crucial for allowing the electrode to move with the muscle during peristaltic waves of contractions. Electrodes were filled with 3 $\mathrm{M} \mathrm{KCl}$ or KAc for recording. Recordings were made with an Axoclamp 2B amplifier (Molecular Devices) in bridge mode and digitized at a sampling rate of 10 $\mathrm{kHz}$ by a Digidata $1320 \mathrm{~A}$ (Axon Instruments). Data were stored using PClamp 8.2 (Molecular Devices) and imported into Spike2 (Cambridge Electronic Design).

\section{Data Analysis}

Preparations were observed through an Olympus BX51WI microscope. The incidence of visible peristaltic waves, including the direction of the waves, was noted manually and marked with electronic timestamps to restrict analysis to these bouts. Activity such as tonic firing, or bursts of action potentials not associated with peristaltic waves, was not included in the analysis. The following criteria had to be met for a preparation to be considered rhythmically active: (1) at least 3 spontaneous and consecutive posterior $(\mathrm{P})$ to anterior $(\mathrm{A})$ or $\mathrm{A}$ to $\mathrm{P}$ waves were recorded, (2) the minimum frequency of the activity was 3 bursts per minute, and (3) the bout was at least 1 minute in duration; bursts occurring more than 1 minute apart were considered to belong to separate bouts.

Criteria to include rhythmic activity in the analysis of the motor pattern were more stringent. In addition to satisfying (1)-(3), only $\mathrm{P}$ to $\mathrm{A}$ wave activity was included, since this was the prevalent type of activity. The determination of wave type had to be both visually confirmed, and supported by appropriate segmental delays in the recordings. The only exceptions to this latter condition were the few single channel recordings that were included based only on visual confirmation of the wave type. Finally, irregu- 
lar bursting activity that could not be distinguished from wave-related activity was not included. These stricter criteria meant that the number of rhythmically active larvae was often larger that the number whose activity were used for quantification of the motor pattern.

Burst start and end times were marked manually in Spike2 by placing cursors at the beginning of the upstroke of the first spike and the beginning of the downstroke of the last spike, respectively. Timestamps were exported as .csv files. Custom code was written in Python version 2.7 to extract burst durations, cycle durations, duty cycles, and quiescence intervals from the preprocessed data. Burst duration was calculated as the time elapsed between the start and end of a burst. Cycle duration was calculated as the time elapsed between start times of successive bursts. Duty cycle was obtained by dividing burst duration by cycle duration. Quiescence interval was calculated as the time elapsed between the end of one burst and the start of the next.

Many previous studies analyzing bursting activity in a population have pooled all observations of a particular measure (e.g. all burst durations), irrespective of the animal in which they were recorded, and performed analyses on these pooled data (e.g. in Drosophila see [21]). This violates the assumption of many statistical tests that the observations in a sample are independent of one another [35]. Multiple bursts gathered from the same animal are not independent measures, and dealing with them as such constitutes pseudoreplication [42]. Instead, quantiles from each measure were calculated for single animals to approximate the individual probability distribution functions. These approximated distributions were then averaged. The average distribution is representative of an average random variable, which can be compared across groups. Each animal is represented only once in the final analysis, thereby avoiding pseudoreplication. Note that the averaging procedure does not assume a particular distribution of the data. This procedure is described in more detail in [50].

Studies of bursting activity often report the mean and standard deviation to compare data sets. However, such measures are only representative when the data are normally distributed. The data obtained from these experiments were not normally distributed (confirmed by tests for normality; data not shown) and thus were poorly described by a single quantity like the mean. Therefore, for each of the measures, the minimum, maximum, and quartile values are reported to give a more complete description of the distribution. The only exceptions are cycle duration and quiescence interval for which precise maximum values are not reported. This is because all groups included animals whose bursting activity was comprised of bouts separated by 1 minute or more. Thus, the maximum cycle duration and quiescence interval were reported as $\geq 60$ seconds. The first quartile (Q1) is the value at or below which $25 \%$ of the data fall in the distribution. The second quartile (Q2), also known as the median, splits the distribution in half. The third quartile (Q3) is the value delineating $75 \%$ of the distribution. To statistically test differences between group distributions, it was necessary to use a nonparametric test, since the assumption of normality was not met. The Mann-Whitney U test (also known as the rank sum test) was used due to its lack of assumptions about the distribution of the data and its ability to test for shifts in one distribution relative to another $[32,35,52]$. The threshold for significance was set at 0.05 .

\section{Results}

\section{slo mutants are rhythmically active}

To investigate the effects of altering slo channel expression on rhythmic motor activity, recordings were made from mutant larvae expressing the $s l o^{1}$ allele. Expression of $s l o^{1}$ has been shown to largely reduce or eliminate the BK current in larval $[40,65,66]$ and adult [16] muscles, and neurons [59]. Dual intracellular recordings were made from dorsal muscles 1 (M1) or 2 (M2) in adjacent abdominal segments in 18 slo $^{1}$ off-midline dissected larvae. Their activity was compared to WT $\left(\mathrm{w}^{1118}\right)$ larvae prepared with the same dissection.

Rhythmic peristaltic wave activity was recorded in 25 of $27(93 \%)$ WT larvae. Both anterior (A) to posterior $(\mathrm{P})$ and $\mathrm{P}$ to $\mathrm{A}$ waves were observed, with the latter the more prevalent type of activity. $\mathrm{P}$ to $\mathrm{A}$ waves were recorded in all 25 larvae $(100 \%)$, while A to $\mathrm{P}$ waves were only recorded in 5 larvae $(20 \%)$. A total of 24 bouts were recorded across 25 larvae, 20 (83\%) of which were comprised of $\mathrm{P}$ to A waves, and $4(17 \%)$ of which were combination bouts including both wave types. No bouts of exclusively A to P waves were recorded. Individual P to A wave bouts ranged from 1 to 9 minutes, while combination bouts 
McKiernan • Slowpoke channels and locomotor activity

lasted 4-9 minutes.

17 of $18 s o^{1}$ larvae (94\%) displayed spontaneous bouts of rhythmic peristaltic activity. As in WT larvae, both $\mathrm{A}$ to $\mathrm{P}$ and $\mathrm{P}$ to $\mathrm{A}$ waves were observed in mutant larvae, with the latter being more prevalent. Of 16 active larvae in which wave type was determined, 15 of 16 (94\%) showed $\mathrm{P}$ to A waves, while just 3 of 16 (19\%) displayed A to P waves. Of 18 total recorded bouts, 14 (78\%) consisted of exclusively $\mathrm{P}$ to $\mathrm{A}$ waves and $4(22 \%)$ of only $\mathrm{A}$ to $\mathrm{P}$ waves. $\mathrm{P}$ to A waves bouts ranged from 1 to 9 minutes, while A to $\mathrm{P}$ wave bouts were between 2 and 6 minutes. Thus, the incidence and duration of rhythmic bouts in $s l^{1}$ larvae was not different from WT ( $\left.\mathrm{p}>0.05\right)$.

\section{slo mutants show faster rhythmic activity than WT}

Next, to determine if the timing of the motor pattern was altered due to slo $^{1}$ expression, $\mathrm{P}$ to $\mathrm{A}$ wave activity was quantified in 21 of 25 active WT larvae and 10 of 17 active $s l^{1}$ larvae. According to the more stringent criteria to include activity in the analysis (see Methods), recordings from 7 mutant larvae were excluded. This represents a larger exclusion percentage $(41 \%)$ than that seen in WT (4 larvae; $16 \%$ ), and was mostly due to irregular bursting that could not be separated from wave-related activity in those animals (Fig. 2C). In other words, though $94 \%$ of $s l^{1}$ larvae were capable of producing rhythmic activity, this group did show an increased propensity for irregular bursting.

Fig. 2 includes representative recordings of $\mathrm{P}$ to A wave activity from $\mathrm{WT}$ and $s l^{1}$ larvae showing a regular, but much faster, motor pattern in mutant animals. Distributions of the relative frequencies of burst duration, cycle duration, duty cycle, and quiescence interval were all clearly shifted relative to WT (Fig. 3). Minimum, maximum, and quartile values for each measure from WT and $s l^{1}$ larvae are presented for comparison in Table 1. Differences between the quartile values revealed that burst durations in mutant larvae were 2.16-2.55 seconds (s) shorter (25-40\% decrease) relative to WT, while cycle durations were shorter by 4.48-4.84 s (35$45 \%$ decrease). The greater decrease in cycle duration relative to burst duration resulted in duty cycles that were larger by $0.06-0.07$ ( $8-9 \%$ increase) in mutant larvae. Quiescence intervals were shorter by 2.03-2.78 s (54-56\% decrease). In sum, expression of the $s l^{1}$ mutant allele decreased burst duration, cy- cle duration, and quiescence interval, and increased duty cycle, relative to WT ( $p<0.001$ on all comparisons).

Rhythmic activity in slo larvae was quantitatively different on all measures from that of WT, demonstrating that altering slo expression in Drosophila larvae significantly alters the timing of the locomotor pattern. However, because the mutant allele was expressed in every cell of the animal, it was not possible from these results to determine in which group(s) of cells the loss of slo channels exerted its effects on the motor pattern. To start addressing specificity, and in particular to explore the influence of MNs on the motor pattern, the next step was to determine whether the observed effects in the mutant could be phenocopied by restricting manipulation of slo expression to identified MNs.

\section{slo RNAi expression in MNs alters cycle, but not burst, duration}

To explore the effects of altering slo expression in MNs, the UAS-GAL4 system [6] was used to target a slo RNAi construct to identified MNs. This UAS-slo RNAi construct has been used previously by others $[41,44]$, and its pan-neuronal expression results in a $\sim 30 \%$ decrease in slo mRNA [63]. Dicer was added to the driver construct to further increase the strength of the knockdown [13]. Expression of slo RNAi was targeted to two identified MNs per nervous system hemisegment, MN1-Ib and MNISNIs [34], using the RRA-GAL4 driver [22]. Dual intracellular recordings were made from the target muscles of these two MNs, MN1 or MN2 [34], in RRAGAL4; UAS-slo RNAi (abbreviated slo RNAi) larvae. Their activity was compared to WT larvae.

22 of 23 slo RNAi larvae (96\%) displayed spontaneous bouts of rhythmic peristaltic activity. As in WT larvae, both A to $\mathrm{P}$ and $\mathrm{P}$ to $\mathrm{A}$ waves were observed in these larvae, with the latter the more frequently recorded activity type. All active larvae showed P to A waves, while only 3 (14\%) displayed A to $\mathrm{P}$ waves. Of 25 total bouts in which wave type was confirmed, $22(88 \%)$ consisted of exclusively $\mathrm{P}$ to A waves and $3(12 \%)$ were combination bouts consisting of both wave types. No bouts comprised of only A to $\mathrm{P}$ waves were recorded in slo RNAi larvae. $\mathrm{P}$ to $\mathrm{A}$ waves bouts ranged from 1 to 10 minutes, while combination bouts were between 6 and 9 minutes. Thus, expression of slo RNAi in identified MNs did not alter the incidence or duration of rhythmic 
McKiernan • Slowpoke channels and locomotor activity

motor activity compared to WT larvae ( $\mathrm{p}>0.05)$.

To determine whether the timing of the motor pattern was altered by slo RNAi expression in MNs, burst duration, cycle duration, duty cycle, and quiescence interval were quantified in all 22 active larvae. Fig. 4 shows representative recordings of $\mathrm{P}$ to $\mathrm{A}$ wave bouts from WT and slo RNAi larvae. The recordings revealed a similar, though slightly faster, motor pattern in slo RNAi animals relative to WT. Shifts in the relative frequency distributions calculated from WT and slo RNAi recordings were seen for all measures, except burst duration (Fig. 5). Minimum, maximum, and quartile values for each measure from WT and slo RNAi larvae are presented for comparison in Table 1. While there was no difference in burst duration between the two groups ( $p>0.05$ ), cycle durations were shorter in slo RNAi compared to WT larvae by $0.38-1.35 \mathrm{~s}$ ( $3-13 \%$ decrease). Since burst duration did not change, while cycle duration decreased, duty cycles were larger by 0.09-0.10 (13$15 \%$ increase) in RNAi larvae. The largest difference between the groups was with respect to quiescence interval, which was smaller in RNAi larvae by 1.55 $1.61 \mathrm{~s}$ (30-42\% decrease) relative to WT. In fact, in some slo RNAi larvae, a low level of tonic firing was present between bursts and no significant period of quiescence was recorded (Fig. 4C), even though regular peristaltic waves were still visually observed. In sum, expression of slo RNAi in MNs decreased cycle duration and quiescence interval and increased duty cycle, relative to WT ( $p<0.001$ on all comparisons), thereby phenocopying 3 of the 4 effects on the motor pattern seen in $s o^{1}$ mutants.

To test whether there was a difference between manipulating slo expression in the whole animal versus in select MNs, a statistical comparison was done between slo ${ }^{1}$ and slo RNAi larvae. Burst durations in slo RNAi larvae were comparable to WT and thus significantly longer than those in $s^{1}{ }^{1}$ mutants (p $<0.001$ ). Cycle durations and quiescence intervals were larger in slo RNAi larvae than in $s^{1} o^{1}$ mutants ( $\mathrm{p}<0.001)$, having decreased to a lesser extent relative to WT. Duty cycles were also slightly larger in slo RNAi compared to slo larvae $(\mathrm{p}<0.01)$. Thus, the two manipulations had qualitatively similar, though quantitatively distinct, effects on the motor pattern.

\section{Discussion}

As genetic techniques identify an increasing number of ion channel genes and splice variants [70,74], the challenge for neurophysiologists is to understand how each of these contribute to the behavioral output of the nervous system. In particular, increasing attention is being paid to the role that currents encoded by specific genes can play in shaping the firing patterns of MNs in response to synaptic input $[30,33,39,49]$. This work explored the effects of manipulating the expression of slowpoke $\mathrm{Ca}^{2+}$ dependent $\mathrm{K}^{+}$channels, in the whole organism and in identified MNs, on the production and timing of rhythmic locomotor activity in Drosophila.

\section{slo mutation does not interfere with produc- tion of rhythmic motor output}

Although expression of a slo mutation in the whole larva resulted in a slight increase in the incidence of irregular bursting, the majority of $s l^{1}$ mutants were able to generate sustained bouts of visible peristaltic waves and corresponding rhythmic motor activity. Similarly, expression of slo RNAi in MNs did not interfere with the ability of the system to produce rhythmic motor output, as measured from the MN muscle targets. These results indicate that either slo currents do not contribute significantly to rhythm generation in the larva, or expression of the manipulations throughout development induced compensatory changes in expression of other ion channels.

Previous work at the Drosphila neuromuscular junction has shown that the voltage-gated A-type $\mathrm{K}^{+}$channel gene, Shaker, is upregulated in slo mutants, helping to correct abnormalities in synaptic transmission caused by the loss of slo channels [43]. An increase in Shaker mRNA has also been observed in Drosophila cultured neurons in response to a reduction in $I_{K C a}$ [55]. Thus, the ability of $s l o^{1}$ and slo RNAi larvae to produce rhythmic motor activity could be due in part to upregulated expression of other $\mathrm{K}^{+}$channels, including but not limited to A-type channels. Similar homeostatic mechanisms that preserve rhythmic motor output in the face of variable current densities, and specifically compensatory upregulation of A-type channels, have been reported in other systems $[46,49]$. Future work to address the issue of homeostatic compensation should include the acute manipulation of slo expression using inducible GAL4 [54]. 
McKiernan • Slowpoke channels and locomotor activity

\section{slo manipulation alters the frequency of rhythmic motor activity}

Genetic manipulation of slo in both the whole animal and identified MNs significantly altered the timing of the motor pattern. slo larvae displayed much faster motor patterns than WT larvae, with substantial decreases in burst duration, cycle duration, and quiescence interval, and an increase in duty cycle. These effects, with the exception of the decrease in burst duration, were phenocopied by expression of slo RNAi in MNs, though the changes were smaller in magnitude than those seen in $s l^{1}$ larvae. It could be that the larger increase in the frequency of motor activity recorded from $s l^{1}$ larvae was due to expression of the mutant allele outside MNs. Or, the relatively less severe phenotype of the slo RNAi larvae could be because the slo mutation results in a more significant loss of functional channels than expression of the RNAi construct [63]. The differences seen between the mutant and RNAi lines could also be due to distinct compensatory mechanisms. While pan-neuronal expression of slo RNAi does not appear to upregulate the expression of $\mathrm{K}^{+}$channels encoded by SK, Shaker, Shal, or eag, slo ${ }^{1}$ mutants do show an increase in eag mRNA. Characterizing how ion channel compensation differs in mutants and RNAi lines will therefore be important when comparing their effects on motor output.

Overall, the results from both sets of experiments demonstrate that manipulating slo expression alters the frequency of rhythmic motor activity underlying crawling. It remains to be determined whether these effects are due only to the loss of slo channels, or due to other changes in ion channel expression that result from manipulating slo. It should be noted that these results regarding the increased frequency of locomotor activity in $s l^{1}$ larvae are in contrast to a previous study [29]. Although they did not fully characterize the motor pattern, Guan et al. (2005) report that the frequency of bursting was reduced in Drosophila slo $^{1}$ larvae relative to WT when recorded at $21^{\circ} \mathrm{C}[29]$. The only obvious distinction between their study and this work was the use of the off-midline dissection method. Larvae dissected off the midline show faster motor activity than those dissected on the midline (Supplemental 1), suggesting sensory feedback in this system contributes to regulating the frequency of locomotor activity, as in other motor systems [27]. However, since the activity of mutant animals was compared only to
WT animals prepared using the same method, the dissection should not have affected the results. At this time, the reason for the discrepancy is unknown, but it is interesting to note that similar conflicting results have been reported in studies of $C$. elegans slo mutants. While some studies have reported that slo mutants display similar or slightly slower rates of locomotion than WT [72], others have reported that these mutants move faster [8]. Even those studies reporting normal rates of locomotion have found that expression of slo mutant alleles can rescue other mutations with inhibitory effects on locomotion (for review see [36]).

\section{Possible mechanisms for regulation of burst- ing frequency by slo currents}

How might slo currents shape the frequency of rhythmic motor activity and, in particular, how could cycle duration be shortened by expression of slo RNAi in MNs? There are at least two possible explanations. The first relates to the specificity of the driver, RRA-GAL4, used to target RNAi expression to identified MNs. In addition to MN1-Ib and MNISN-Is, RRA-GAL4 expresses in an interneuron known by its embryonic identity as the posterior corner cell, pCC [22]. Therefore, in the experiments described herein slo RNAi was likely also expressed in pCC. If $\mathrm{pCC}$ provides input to $\mathrm{MNs}$, either directly or indirectly, then a change in the activity of this interneuron could explain a change in cycle duration. Future experiments to determine the role of $\mathrm{pCC}$ in producing the locomotor phenotype observed in slo RNAi larvae could include the mosaic expression of slo RNAi using the flippase/FLP recognition target (FLP/FRT) system [24]. Larvae could be screened and only those without pCC expression recorded to see whether the decrease in cycle duration is still observed. If such studies support a role for pCC in regulating the frequency of MN bursting, it would be the first identification, to the author's knowledge, of a specific interneuron contributing to generation of crawling rhythms in Drosophila. Identification of such a neuron could pave the way for studies of motor circuitry using the advanced genetic tools for which this model system is renowned.

On the other hand, it is possible that expression of slo RNAi in MNs, and not pCC, was responsible for the decrease in cycle duration. The role of MN currents in shaping rhythmic motor activity is a subject of active research $[30,33,39,49]$. Much of 
the recent work has focused on the role of persistent inward currents in MNs $[17,47,58]$, but outward currents have also been shown to shape MN firing during rhythmic activity $[37,47,56,62]$. In particular, a recent study in Drosophila showed that elimination of Shal-mediated currents in MNs, via expression of a dominant negative construct under the control of RRA-GAL4, altered the frequency of larval crawling [56]. The results from the RNAi experiments reported herein add to an increasing body of work suggesting that MN outward currents, and BK currents in particular, may enable MNs to shape the timing of rhythmic motor output. Specifically, the large decrease in quiescence interval in slo RNAi larvae suggests that slo currents may act in MNs as a hyperpolarizing force following a burst [75]. Such a force would counteract inward currents to keep MNs from firing, contributing to the creation of a period of quiescence. Reduction or elimination of slo currents would shorten the quiescence interval and thereby decrease the cycle duration, as observed in this study.

Previous studies have reported that blocking BK channels decreases quiescence interval and burst duration [71, 75]. Womack et al. (2004) hypothesized that BK channels provide a hyperpolarizing influence between bursts, producing quiescence. To explain why blocking BK channels shortened quiescence interval while also decreasing, rather than increasing, burst duration, they speculate that BK channels activate late or after bursting has ceased. Another mechanism, not involving BK channels, terminates the bursts. They go on to explain that the burst-terminating mechanism can activate sooner when BK channels are blocked, causing the decrease in burst duration. Similarly, in Drosophila larvae, slo channels may maximally activate late, after another mechanism has already terminated, or is in the process of terminating, the burst. This could explain why slo RNAi larvae showed no change in burst duration, even though quiescence interval decreased. If in some neurons a reduction in slo channel expression also allows whatever mechanism terminates bursts to do so sooner, this could explain why burst duration decreased in $s l^{1}$ mutants.

A recent study by Pulver et al. (2010) reported that after-hyperpolarizations following bursts in Drosophila larval MNs are mediated by the $\mathrm{Na}^{+} / \mathrm{K}^{+}$ATPase, and not by $I_{K C a}[57]$. However, their results are not necessarily in conflict with the hypothesis that slo currents contribute to setting the quiescence interval. First, it is possible that slo currents may counteract inward currents and keep the cell from firing without producing a measurable after-hyperpolarization. Second, and mentioned by the authors themselves, is the importance of looking at endogenous activity when examining the role of a particular current. Rather than recording spontaneous bursting in MNs, the authors stimulated MNs with trains of square pulses at a frequency designed to mimic rhythmic synaptic input. The activation (and inactivation) of ionic currents could be very different in response to square-pulse stimulation, as opposed to endogenous synaptic input. Intracellular recordings from MNs during spontaneous locomotor activity, as recently described by others [62], will be crucial for determining what currents contribute when bursting is driven by endogenous inputs.

\section{Limitations, open questions, and future direc- tions}

The biggest limitation of the current work is the lack of a full characterization of the slo RNAi knockdown. Preliminary RT-PCR results indicate that pan-neuronal expression of the UAS-slo RNAi construct under the control of elav-GAL4 produces a $\sim 30 \%$ decrease in slo mRNA when quantified in the whole nervous system [63] However, these data do not indicate the extent of the reduction in slo mRNA in the MNs targeted in this study. It is possible manipulation of slo was unsuccessful or insignificant in all or some MNs, though this seems unlikely since in that case one would not expect to observe changes in the motor pattern relative to $\mathrm{WT}$, as were presented.

However, if the manipulation was successful in some and not other animals, this could potentially change the interpretation of the results. For example, the distribution of burst durations in slo RNAi larvae largely overlaps with the WT distribution (Fig. 5), leading to the conclusion that slo manipulation does not affect burst termination in larval MNs. The distribution does include, however, a small tail consisting of a few recordings in which some burst durations were longer than those recorded in WT. If the knockdown was more effective in these animals, this could explain these outlying values and suggest that slo currents may play a role in burst termination. In contrast, the distributions for other measures such as cycle duration and quiescence interval, where it was concluded that the knockdown had an effect, do not show any obvious tails or bi- 
modalities that would indicate distinct efficacies of the knockdown.

To conclude whether there is a relationship between the extent of the knockdown in a particular $\mathrm{MN}$ and the recorded motor pattern would require performing one of two possible experiments. First, one could record from the animal and later perform single cell RT-PCR on MNs expressing the knockdown to measure the amount of slo mRNA. A second possibility is that one could record the motor pattern and later do patch clamp recordings from MNs using pharmacology to isolate and measure the slo current. Both options present significant technical challenges, but are potential future directions. A less technically challenging, but also less informative, approach would be to patch on to several MNs to determine the percentage showing a significant reduction in slo current and correlate that with the percentage of animals showing a change in motor pattern.

Additional limitations relate to information about the model system itself. The slo current has not been fully characterized in larval MNs. It remains unclear whether slo channels carry transient and/or sustained $\mathrm{Ca}^{2+}$-dependent $\mathrm{K}^{+}$currents, and to what extent these currents contribute to the whole-cell current in larval MNs. This information is vital to understanding the effects of slo knockdown on MN excitability. Obtaining this information will require patch clamp recordings using pharmacological blockers specific to the slo current to isolate it from other $\mathrm{Ca}^{2+}$-dependent currents in MNs. In addition, the circuitry of the putative locomotor CPG is unknown in this system. An understanding of the network connectivity, and in particular whether MNs participate in generating the rhythm itself (as in the crustacean STG [48]) is crucial for interpreting the observed changes in the frequency of the locomotor rhythm. To map the circuitry of the CPG will be challenging and require a clever combination of genetic techniques and simultaneous recordings from neurons in multiple regions of the larval nervous system.

\section{Conclusions}

The current work shows that manipulating the expression of slo channels significantly alters the timing of locomotor activity in Drosophila larvae, and specifically points to the importance of MN currents in shaping motor output. Several questions remain open regarding exactly how slo currents affect MN firing and how changes in MN excitability may interact with synaptic inputs to alter the frequency of motor activity. Alternative hypotheses and possible experiments have been outlined that, if completed, will shed more light on this motor system, and more generally on our understanding of motor control. It is hoped that this work will serve as a basis for future studies on the role of slo channels in locomotor behavior and the investigation of the relative contribution of network versus MN intrinsic properties in the generation of rhythmic motor output.

\section{Acknowledgements}

The author thanks Marco A. Herrera Valdez for valuable feedback on earlier versions of this manuscript.

\section{Funding}

At the time the work was carried out, ECM was funded in part by the Interdisciplinary Graduate Program in Physiological Sciences at the University of Arizona. All experiments were performed at Arizona State University, School of Life Sciences. [Pending receipt of details regarding specific grants, additional funding information will be added during revisions.]

\section{Figure captions}

Figure 1: Off-midline larval preparation. A cut (dashed line) was made to the right of the midline near muscle 4. Larvae were pinned and cleaned so that the muscles (rectangles) and the central nervous system (solid black) were exposed. Muscles 1,2,4,6,7 and abdominal segments A5-A7 are labeled. For clarity, not all muscles, segments, or nerves are pictured.

Figure 2: slo $^{1}$ mutant larvae display altered rhythmic motor output. A. Dual intracellular recordings from WT (top two traces) and slo ${ }^{1}$ (bottom two traces) larvae. Activity was recorded during $\mathrm{P}$ to A waves in adjacent M1's of segments A4 and A5, as indicated. Scale bar is 10 seconds. B. Enlargement of dual recordings in A from WT and slo larvae. Scale bar is 2 seconds. C. Examples of irregular bursting activity not associated with peristaltic waves recorded in two slo $^{1}$ larvae. Scale bar is 10 seconds. 
Figure 3: Quantification of motor activity in $s l^{1}$ larvae. Distributions of the relative frequencies of burst durations (A.), cycle durations (B.), duty cycles (C.), and quiescence intervals (D.) for WT (black) and $s l o^{1}$ (white) larvae.

Figure 4: slo RNAi larvae show altered rhythmic motor output. A. Dual intracellular recordings from WT (top two traces; from same recording as shown in Fig. 2A) and larvae expressing slo RNAi under the control of RRA-GAL4 (bottom two traces) during P to A waves. Scale bar 10 seconds. B. Enlargements of recordings in $\mathbf{A}$ for WT and slo RNAi larvae. Scale bar 2 seconds. C. Recording from slo RNAi larva showing low-level tonic firing between bursts. Top scale bar 10 seconds, bottom scale bar 2 seconds.

Figure 5: Quantification of motor activity in slo RNAi larvae. Distributions of the relative frequencies of burst durations (A.), cycle durations (B.), duty cycles (C.), and quiescence intervals (D.) for WT (black) and slo RNAi (white) larvae.

\section{Tables}

Table 1: Measures of motor pattern in WT, slo $^{1}$, and slo RNAi larvae 


\section{References}

[1] N.S. Atkinson, R. Brenner, R.A. Bohm, J.Y. Yu, and J.L. Wilbur. Behavioral and electrophysiological analysis of Ca-activated K-channel transgenes in Drosophila. Ann. NY Acad. Sci., 860:296-305, 1998.

[2] N.S. Atkinson, R. Brenner, W. Chang, J. Wilbur, J.L. Larimer, and J. Yu. Molecular separation of two behavioral phenotypes by a mutation affecting the promoters of a Ca-activated K channel. Journal of Neuroscience, 20(8):2988-2993, 2000.

[3] N.S. Atkinson, G.A. Robertson, and B. Ganetzky. A component of calcium-activated potassium channels encoded by the Drosophila slo locus. Science, 253(5019):551-555, 1991.

[4] J.W. Barclay and H.L. Atwood. Impairment of central pattern generation in Drosophila cysteine string protein mutants. J. Comp. Physiol. A, 188:71-78, 2002.

[5] N. Benhassine and T. Berger. Large-conductance calcium-dependent potassium channels prevent dendritic excitability in neocortical pyramidal neurons. Pflügers Archiv European Journal of Physiology, 457(5):1133-1145, 2009.

[6] A.H. Brand and N. Perrimon. Targeted gene expression as a means of altering cell fates and generating dominant phenotypes. Development, 118(2):401415, 1993.

[7] R. Brenner, J.Y. Yu, K. Srinivasan, L. Brewer, J.L. Larimer, J.L. Wilbur, and N.S. Atkinson. Complementation of physiological and behavioral defects by a Slowpoke $\mathrm{Ca}^{2+}$-activated $\mathrm{K}^{+}$channel transgene. Journal of Neurochemistry, 75(3):1310-1319, 2000.

[8] M. Carre-Pierrat, K. Grisoni, K. Gieseler, M.C. Mariol, E. Martin, M. Jospin, B. Allard, and L. Ségalat. The SLO-1 BK channel of Caenorhabditis elegans is critical for muscle function and is involved in dystrophin-dependent muscle dystrophy. Journal of Molecular Biology, 358(2):387-395, 2006.

[9] D. Cattaert and S. Birman. Blockade of the central generator of locomotor rhythm by noncompetitive NMDA receptor antagonists in Drosophila larvae. Journal of Neurobiology, 48(1):58-73, 2001.

[10] M.F. Ceriani, J.B. Hogenesch, M. Yanovsky, S. Panda, M. Straume, and S.A. Kay. Genomewide expression analysis in Drosophila reveals genes controlling circadian behavior. Journal of Neuroscience, 22(21):9305, 2002.

[11] R.L. Cooper and W.S. Neckameyer. Dopaminergic modulation of motor neuron activity and neuromuscular function in drosophila melanogaster. Comp
Biochem Physiol B Biochem Mol Biol., 122(2):199210, 1999.

[12] C.A. del Negro, C.F. Hsiao, and S.H. Chandler. Outward currents influencing bursting dynamics in guinea pig trigeminal motoneurons. Journal of Neurophysiology, 81(4):1478-1485, 1999.

[13] G. Dietzl, D. Chen, F. Schnorrer, K.C. Su, Y. Barinova, M. Fellner, B. Gasser, K. Kinsey, S. Oppel, S. Scheiblauer, A. Couto, V. Marra, K. Keleman, and B.J. Dickson. A genome-wide transgenic RNAi library for conditional gene inactivation in Drosophila. Nature, 448(7150):151-156, 2007.

[14] W. Du, J.F. Bautista, H. Yang, A. Diez-Sampedro, S.A. You, L. Wang, P. Kotagal, H.O. Luders, J. Shi, J. Cui, et al. Calcium-sensitive potassium channelopathy in human epilepsy and paroxysmal movement disorder. Nature Genetics, 37(7):733-738, 2005.

[15] T. Elkins and B. Ganetzky. The roles of potassium currents in Drosophila flight muscles. Journal of Neuroscience, 8(2):428-4334, 1988.

[16] T. Elkins, B. Ganetzky, and C.F. Wu. A Drosophila mutation that eliminates a calciumdependent potassium current. PNAS, 83(21):84158419, 1986.

[17] M. Enríquez Denton, J. Wienecke, M. Zhang, H. Hultborn, and P.A. Kirkwood. Voltagedependent amplification of synaptic inputs in respiratory motoneurones. Journal of Physiology, 2012.

[18] E.S. Faber and P. Sah. Calcium-activated potassium channels: multiple contributions to neuronal function. Neuroscientist, 9(3):181-194, 2003.

[19] Y. Feng, A. Ueda, and C.F. Wu. A modified minimal hemolymph solution, HL3.1, for physiological recordings at the neuromuscular junction of normal and mutant Drosophila larvae. Journal of Neurogenetics, 18(2):377-402, 2004.

[20] M.P. Fernández, J. Chu, A. Villella, N. Atkinson, S.A. Kay, and M.F. Ceriani. Impaired clock output by altered connectivity in the circadian network. PNAS, 104(13):5650, 2007.

[21] L.E. Fox, D.R. Soll, and C.F. Wu. Coordination and modulation of locomotion pattern generators in drosophila larvae: Effects of altered biogenic amine levels by the tyramine b hydroxlyase mutation. Journal of Neuroscience, 26(5):1486-1498, 2006.

[22] M. Fujioka, B.C. Lear, M. Landgraf, G.L. Yusibova, J. Zhou, K.M. Riley, N.H. Patel, and J.B. Jaynes. Even-skipped, acting as a repressor, regulates axonal projections in Drosophila. Development, 130(22):5385, 2003. 
McKiernan • Slowpoke channels and locomotor activity

[23] M. Gho and B. Ganetzky. Analysis of repolarization of presynaptic motor terminals in Drosophila larvae using potassium-channel-blocking drugs and mutations. Journal of Experimental Biology, 170(1):93, 1992.

[24] K.G. Golic and S. Lindquist. The FLP recombinase of yeast catalyzes site-specific recombination in the Drosophila genome. Cell, 59(3):499-509, 1989.

[25] M. Gorassini, D.J. Bennett, O. Kiehn, T. Eken, and H. Hultborn. Activation patterns of hindlimb motor units in the awake rat and their relation to motoneuron intrinsic properties. Journal of Neurophysiology, 82(2):709-717, 1999.

[26] S. Grillner. Biological pattern generation: the cellular and computational logic of networks in motion. Neuron, 52(5):751-766, 2006.

[27] S. Grillner, T. Deliagina, A. El Manira, RH Hill, A. Lansner, GN Orlovsky, and P Wallen. Neural networks that co-ordinate locomotion and body orientation in lamprey. Trends in Neurosciences, 18(6):270-279, 1995.

[28] N. Gu, K. Vervaeke, and J.F. Storm. BK potassium channels facilitate high-frequency firing and cause early spike frequency adaptation in rat CA1 hippocampal pyramidal cells. Journal of Physiology, 580(Pt.3):859-882, 2007.

[29] Z. Guan, S. Saraswati, B. Adolfsen, and J.T. Littleton. Genome-wide transcriptional changes associated with enhanced activity in the Drosophila nervous system. Neuron, 48(1):91-107, 2005.

[30] RM Harris-Warrick. Voltage-sensitive ion channels in rhythmic motor systems. Current Opinion in Neurobiology, 12:646-651, 2002.

[31] R.M. Harris-Warrick. General principles of rhythmogenesis in central pattern networks. Progress in Brain Research, 187:213, 2010.

[32] A. Hart. Mann-Whitney test is not just a test of medians: differences in spread can be important. British Medical Journal, 323(7309):391, 2001.

[33] CJ Heckman, C. Mottram, K. Quinlan, R. Theiss, and J. Schuster. Motoneuron excitability: the importance of neuromodulatory inputs. Clinical Neurophysiology, 120(12):2040-2054, 2009.

[34] B. Hoang and A. Chiba. Single-cell analysis of Drosophila larval neuromuscular synapses. Developmental Biology, 229(1):55-70, 2001.

[35] P.G. Hoel, S.C. Port, and C.J. Stone. Introduction to statistical theory. Houghton-Mifflin, 1971.

[36] L. Holden-Dye, V. O'Connor, N.A. Hopper, R.J. Walker, A. Harder, K. Bull, and M. Guest. SLO,
SLO, quick, quick, slow: calcium-activated potassium channels as regulators of Caenorhabditis elegans behaviour and targets for anthelmintics. Invertebrate Neuroscience, 7(4):199-208, 2007.

[37] S.L. Hooper, E. Buchman, A.L. Weaver, J.B. Thuma, and K.H. Hobbs. Slow conductances could underlie intrinsic phase-maintaining properties of isolated lobster (Panulirus interruptus) pyloric neurons. Journal of Neuroscience, 29(6):1834-1845, 2009.

[38] J. Hounsgaard, H. Hultborn, B. Jespersen, and O. Kiehn. Intrinsic membrane properties causing a bistable behaviour of $\alpha$-motoneurones. Experimental Brain Research, 55(2):391-394, 1984.

[39] O. Kiehn, M.C. Tresch O. Kjaerulff, and R.M. Harris-Warrick. Contributions of intrinsic motor neurons properties to the production of rhythmic motor output in the mammalian spinal cord. Brain Research Bulletin, 53(5):649-659, 2000.

[40] A. Komatsu, S. Singh, P. Rathe, and C.F. Wu. Mutational and gene dosage analysis of calciumactivated potassium channels in Drosophila: Correlation of micro- and macroscopic currents. PNAS, 99(20):13232-13237, 1990.

[41] Y. Kwon, D.S. Ronderos, Y. Lee, B. Akitake, O.M. Woodward, W.B. Guggino, D.P. Smith, and C. Montell. Drosophila TRPA1 channel is required to avoid the naturally occurring insect repellent citronelial. Current Biology, 20(18):1672-1678, 2010.

[42] S.E. Lazic. The problem of pseudoreplication in neuroscientific studies: is it affecting your analysis? $B M C$ neuroscience, 11(1):5, 2010.

[43] J. Lee, A. Ueda, and C.F. Wu. Pre- and postsynaptic mechanisms of synaptic strength homeostasis revealed by Slowpoke and Shaker $\mathrm{K}^{+}$ channel mutations in Drosophila. Neuroscience, 154(4):1283-1296, 2008.

[44] J. Lee and C.F. Wu. Orchestration of Stepwise Synaptic Growth by $\mathrm{K}^{+}$and $\mathrm{Ca}^{2+}$ Channels inDrosophila. Journal of Neuroscience, 30(47):1582115833, 2010.

[45] S. Liu and M.T. Shipley. Multiple conductances cooperatively regulate spontaneous bursting in mouse olfactory bulb external tufted cells. Journal of $\mathrm{Neu}$ roscience, 28(7):1625-1639, 2008.

[46] J.N. MacLean, Y. Zhang, B.R. Johnson, and R.M. Harris-Warrick. Activity-independent homeostasis in rhythmically active neurons. Neuron, 37(1):109120, 2003.

[47] M. Manuel, Y. Li, S.M. ElBasiouny, K.C. Murray, A.L. Griener, C.J. Heckman, and D.J. Bennett. 
McKiernan • Slowpoke channels and locomotor activity

Nmda induces persistent inward and outward currents that cause rhythmic bursting in adult rodent motoneurons. Journal of Neurophysiology, 2012.

[48] E. Marder and D. Bucher. Central pattern generators and the control of rhythmic movements. Current Biology, 11:R986-R996, 2001.

[49] E. Marder and J.M. Goaillard. Variability, compensation and homeostasis in neuron and network function. Nature Reviews Neuroscience, 7(7):563574, 2006.

[50] E.C. McKiernan. The role of specific voltageactivated and calcium-activated potassium currents in shaping motor neuron firing output during rhythmic motor activity. $\mathrm{PhD}$ thesis, The University of Arizona, 2010. Available at: http://hdl.handle.net/10150/145732.

[51] J.G. McLarnon. Potassium currents in motoneurones. Progr. Neurobiol., 47(6):513-531, 1995.

[52] W. Mendenhall and L. Ott. Understanding statistics. Duxbury Press, Wadsworth Inc., 1980.

[53] A.L. Meredith, K.S. Thorneloe, M.E. Werner, M.T. Nelson, and R.W. Aldrich. Overactive bladder and incontinence in the absence of the BK large conductance $\mathrm{Ca}^{2+}$-activated $\mathrm{K}^{+}$channel. Journal of Biological Chemistry, 279(35):36746, 2004.

[54] T. Osterwalder, K.S. Yoon, B.H. White, and H. Keshishian. A conditional tissue-specific transgene expression system using inducible GAL4. PNAS, 98(22):12596-12601, 2001.

[55] I. Peng and C.F. Wu. Drosophila cacophony channels: a major mediator of neuronal $\mathrm{Ca}^{2+}$ currents and a trigger for $\mathrm{K}^{+}$channel homeostatic regulation. Journal of Neuroscience, 27(5):1072, 2007.

[56] Y. Ping, G. Waro, A. Licursi, S. Smith, D.A. Vo-Ba, and S. Tsunoda. Shal/Kv4 channels are required for maintaining excitability during repetitive firing and normal locomotion in Drosophila. PLoS ONE, 6(1):e16043, 2011.

[57] S.R. Pulver and L.C. Griffith. Spike integration and cellular memory in a rhythmic network from $\mathrm{Na}^{+} / \mathrm{K}^{+}$pump current dynamics. Nature Neuroscience, 13(1):53-60, 2010.

[58] A.L. Revill and A.J. Fuglevand. Effects of persistent inward currents, accommodation, and adaptation on motor unit behavior: a simulation study. Journal of Neurophysiology, 106(3):1467-1479, 2011.

[59] M. Saito and CF Wu. Expression of ion channels and mutational effects in giant Drosophila neurons differentiated from cell division-arrested embryonic neuroblasts. Journal of Neuroscience, 11(7):21352150, 1991.
[60] L. Salkoff, A. Butler, G. Ferreira, C. Santi, and A. Wei. High-conductance potassium channels of the SLO family. Nature Reviews Neuroscience, 7(12):921-931, 2006.

[61] M. Sausbier, H. Hu, C. Arntz, S. Feil, S. Kamm, H. Adelsberger, U. Sausbier, CA Sailer, R. Feil, F. Hofmann, et al. Cerebellar ataxia and Purkinje cell dysfunction caused by $\mathrm{Ca}^{2+}$-activated $\mathrm{K}^{+}$channel deficiency. PNAS, 101(25):9474, 2004.

[62] J.E. Schaefer, J.W. Worrell, and R.B. Levine. Role of intrinsic properties in Drosophila motoneuron recruitment during fictive crawling. Journal of $\mathrm{Neu}$ rophysiology, 104(3):1257-1266, 2010.

[63] K. Scheckel. Potassium channel expression in the larval Drosophila melanogaster CNS. In Annual Meeting of the American Association for the Advancement of Science, Washington, D.C., Feb. 1721 2011. Retrieved Dec. 6, 2012 from: https://cbs. asu.edu/sites/default/files/scheckel_poster2.pdf.

[64] L.R. Shao, R. Halvorsrud, L. Borg-Graham, and J.F. Storm. The role of BK-type $\mathrm{Ca}^{2+}$-dependent $\mathrm{K}^{+}$channels in spike broadening during repetitive firing in rat hippocampal pyramidal cells. Journal of Physiology, 521(1):135-146, 1999.

[65] S. Singh and CF Wu. Complete separation of four potassium currents in Drosophila. Neuron, 2(4):1325-1329, 1989.

[66] S. Singh and C.F. Wu. Properties of potassium currents and their role in membrane excitability in Drosophila larval muscle fibers. Journal of Experimental Biology, 152:59, 1990.

[67] W. Song, M. Onishi, L.Y. Jan, and Y. N. Jan. Peripheral multidendritic sensory neurons are necessary for rhythmic locomotion behavior in Drosophila larvae. PNAS, 104(12):5199-5204, 2007.

[68] Q. Sun and N. Dale. Developmental changes in expression of ion currents accompany maturation of locomotor pattern in frog tadpoles. Journal of Physiology, 507(1):257-264, 1998.

[69] A. Ueda and C.F. Wu. Distinct frequencydependent regulation of nerve terminal excitability and synaptic transmission by $\mathrm{I}_{A}$ and $\mathrm{I}_{K}$ potassium channels revealed by Drosophila Shaker and Shab mutations. Journal of Neuroscience, 26(33):62386248, 2006.

[70] H. Vacher, D.P. Mohapatra, and J.S. Trimmer. Localization and targeting of voltage-dependent ion channels in mammalian central neurons. Physiological Reviews, 88(4):1407-1447, 2008.

[71] G.Y. Wang, B.A. Olshausen, and L.M. Chalupa. Differential effects of apamin-and charybdotoxinsensitive $\mathrm{K}^{+}$conductances on spontaneous dis- 
McKiernan • Slowpoke channels and locomotor activity

charge patterns of developing retinal ganglion cells. Journal of Neuroscience, 19(7):2609, 1999.

[72] Z.W. Wang, O. Saifee, M.L. Nonet, L. Salkoff, et al. Slo-1 potassium channels control quantal content of neurotransmitter release at the c. elegans neuromuscular junction. Neuron, 32(5):867-882, 2001.

[73] L.C. Warbington, T. Hillman, C. Adams, and M. Stern. Reduced transmitter release conferred by mutations in the slowpoke-encoded $\mathrm{Ca}^{2+}$-activated $\mathrm{K}^{+}$channel gene of Drosophila. Invertebrate Neuroscience, 2(1):51-60, 1996.
[74] D. Wicher, C. Walther, and C. Wicher. Nonsynaptic ion channels in insects-basic properties of currents and their modulation in neurons and skeletal muscles. Progr. Neurobiol., 64(5):431-525, 2001.

[75] M.D. Womack and K. Khodakhah. Dendritic control of spontaneous bursting in cerebellar Purkinje cells. Journal of Neuroscience, 24(14):3511-3521, 2004.

[76] T.M. Wright Jr and R.L. Calabrese. Contribution of motoneuron intrinsic properties to fictive motor pattern generation. Journal of Neurophysiology, 106(2):538-553, 2011. 
Figure 1

Off midline larval preparation.

Intracellular electrodes

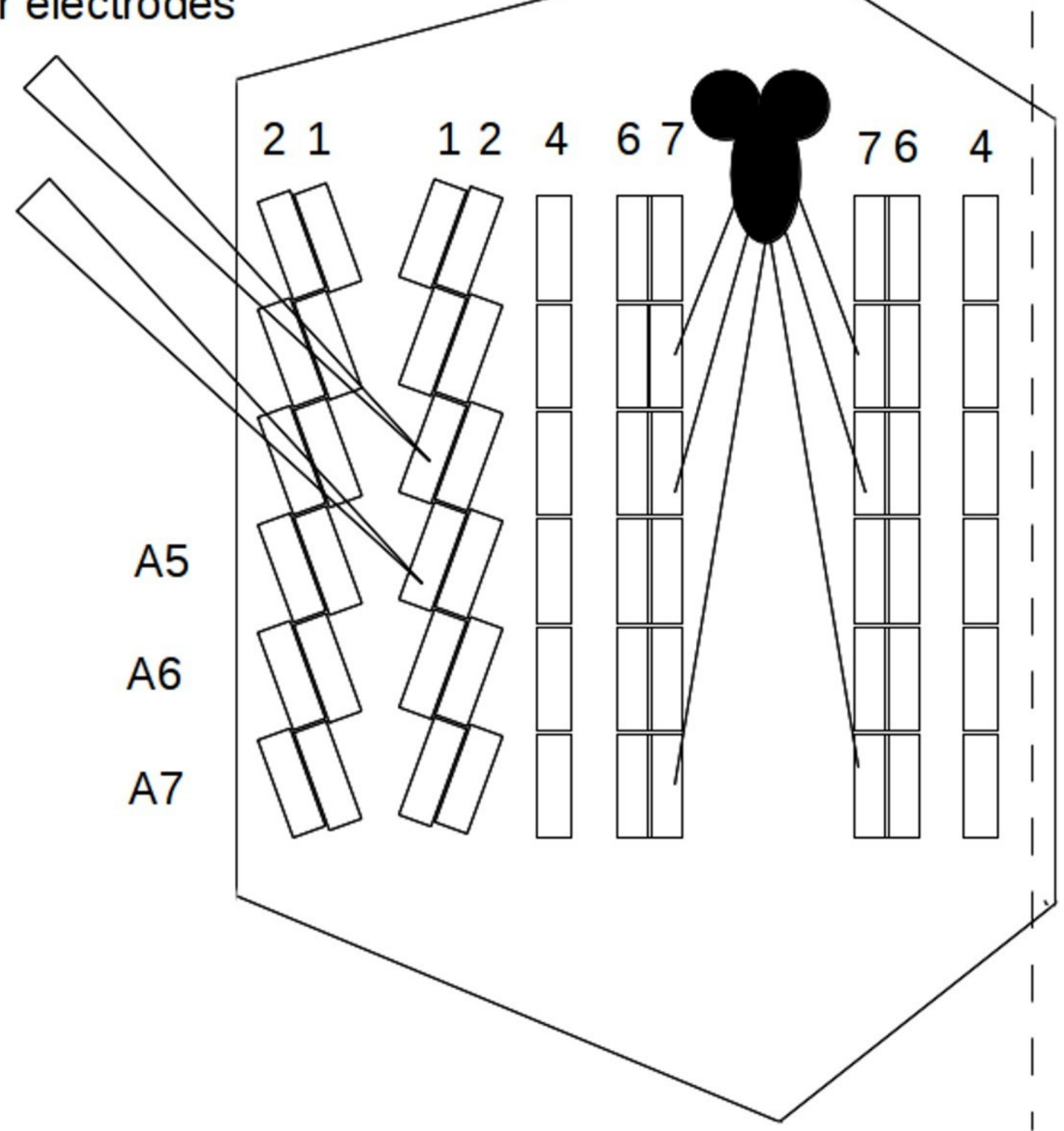




\section{Figure 2}

slo ${ }^{1}$ mutant larvae display altered rhythmic motor output.

A. WT

M1, A5

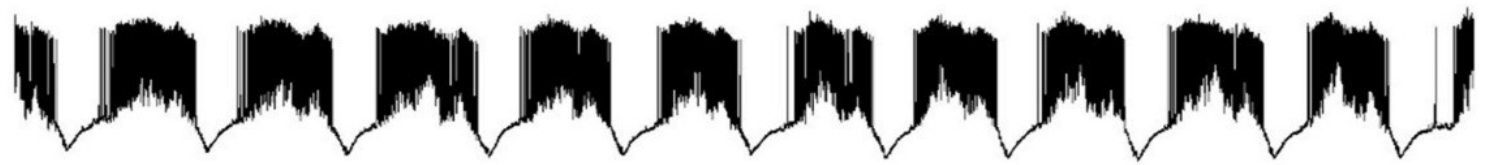

$\mathrm{M} 1, \mathrm{~A} 4$

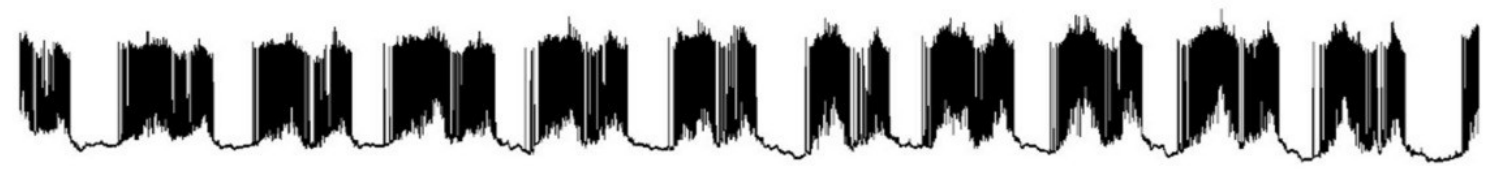

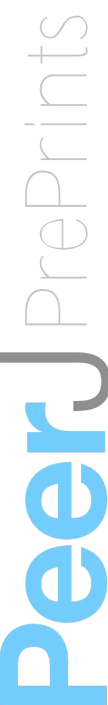

Slo

B.

WT
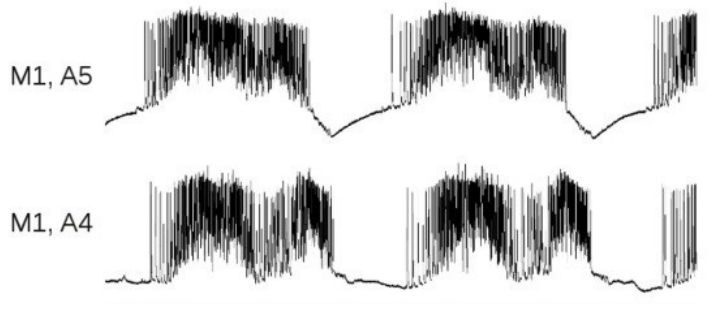

Slo

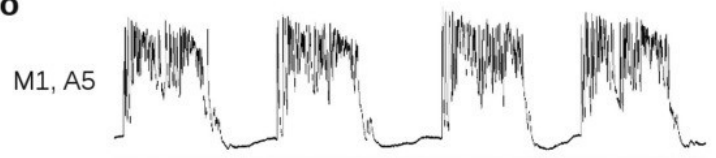

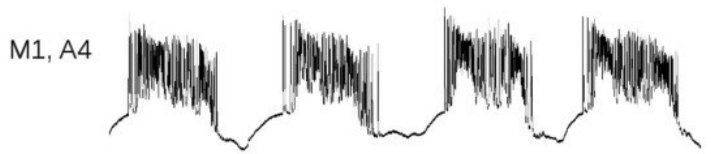

C.

Slo

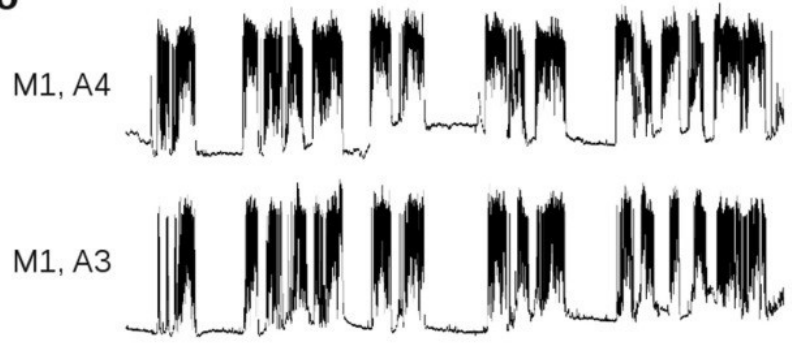

U.

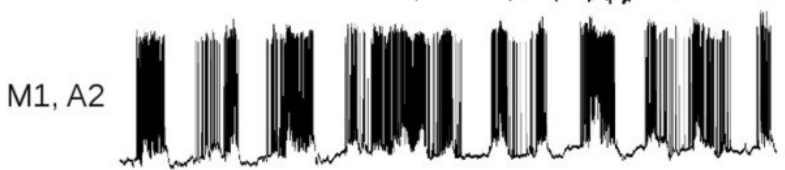


Figure 3

Quanti
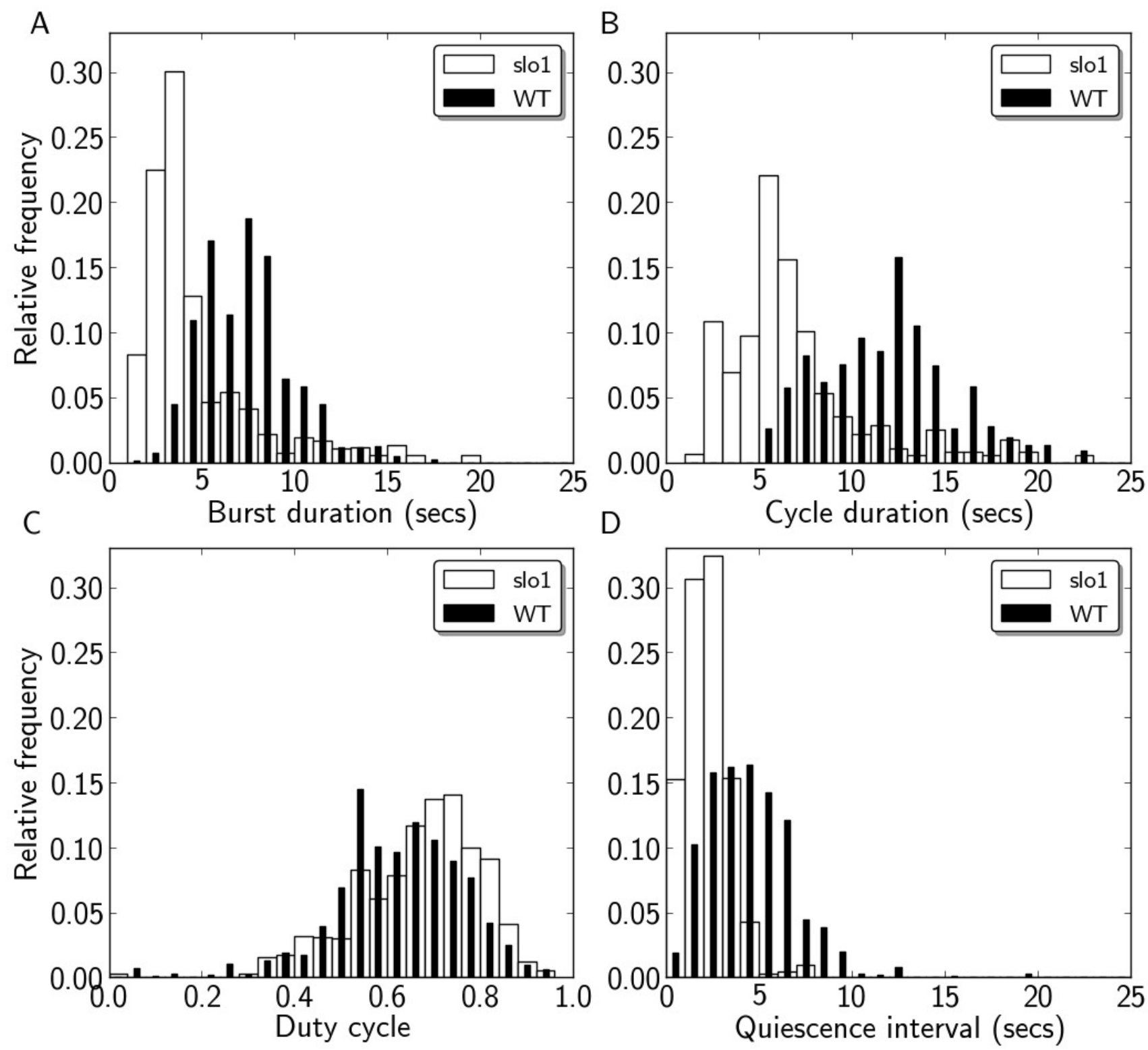


\section{Table $\mathbf{1}_{\text {(on next page) }}$}

Measures of motor pattern in WT, slo ${ }^{1}$, and slo RNAi larvae 
Table 1: Measures of motor pattern in WT, slo ${ }^{1}$, and slo RNAi larvae

\begin{tabular}{llllllllll}
\hline genotype & measure & $\mathrm{n}$ & $\min (\mathrm{s})$ & $\max (\mathrm{s})$ & $\mathrm{Q} 1(\mathrm{~s})$ & $\mathrm{Q} 2(\mathrm{~s})$ & $\mathrm{Q} 3(\mathrm{~s})$ & $\mathrm{p}$-value ${ }^{a}$ & $\mathrm{p}_{\text {-value }}^{b}$ \\
\hline WT & & & & & & & & & \\
& burst duration & 21 & 1.61 & 17.21 & 6.32 & 7.19 & 8.44 & - & - \\
& cycle duration & 21 & 5.19 & $\geq 60$ & 10.66 & 11.81 & 12.93 & - & - \\
& duty cycle & 21 & 0.05 & 0.93 & 0.57 & 0.63 & 0.69 & - & - \\
& quiescence interval & 21 & 0.59 & $\geq 60$ & 3.63 & 4.35 & 5.18 & - & - \\
slo $^{1}$ & & & & & & & & & \\
& & 10 & 1.15 & 27.35 & 3.77 & 4.78 & 6.28 & $<0.001$ & - \\
& burst duration & 10 & 1.89 & $\geq 60$ & 5.81 & 6.94 & 8.45 & $<0.001$ & - \\
& cycle duration & 10 & 0.03 & 0.96 & 0.63 & 0.69 & 0.75 & $<0.001$ & - \\
& duty cycle & 10 & 0.26 & $\geq 60$ & 1.60 & 1.92 & 2.39 & $<0.001$ & - \\
slo RNAi & quiescence interval & & & & & & & & \\
& & & & & & & & & \\
& burst duration & 22 & 2.35 & 29.72 & 6.44 & 7.73 & 9.41 & $>0.05$ & $>0.05$ \\
& cycle duration & 22 & 4.91 & $\geq 60$ & 9.31 & 10.62 & 12.55 & $<0.001$ & $<0.001$ \\
& duty cycle & 22 & 0.08 & 0.98 & 0.67 & 0.73 & 0.79 & $<0.001$ & $<0.01$ \\
& quiescence interval & 22 & 0.33 & $\geq 60$ & 2.09 & 2.74 & 3.60 & $<0.001$ & $<0.001$ \\
\hline
\end{tabular}

${ }^{a}$ Mann-Whitney U Test/Wilcoxon rank-sum test, compared to WT

${ }^{b}$ Mann-Whitney U Test/Wilcoxon rank-sum test, compared to slo ${ }^{1}$ 


\section{Figure 4}

slo RNAi larvae show altered rhythmic motor output.

A. WT

M1, A5

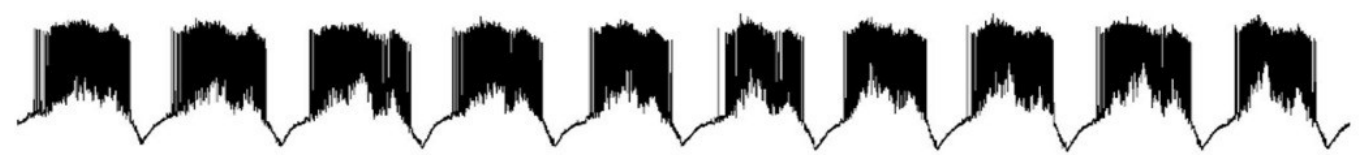

$\mathrm{M} 1, \mathrm{~A} 4$

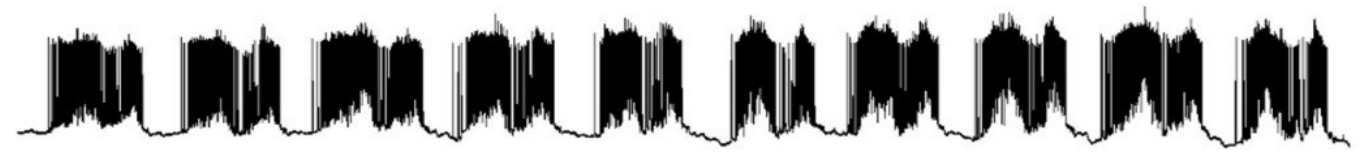

RRA;Slo

$\mathrm{M} 1, \mathrm{~A} 5$

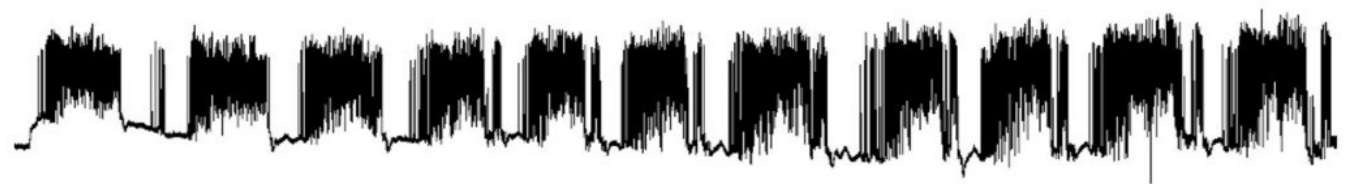

M1, A4

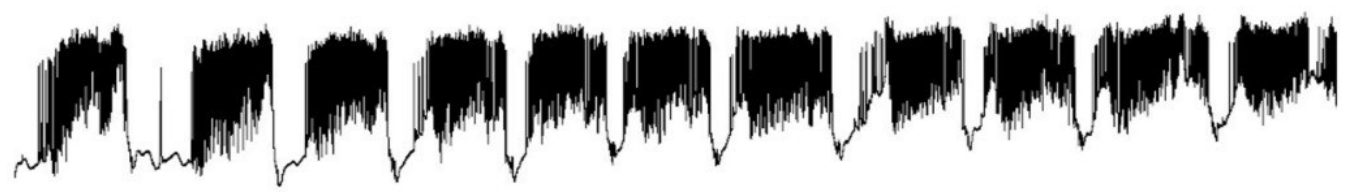

B.

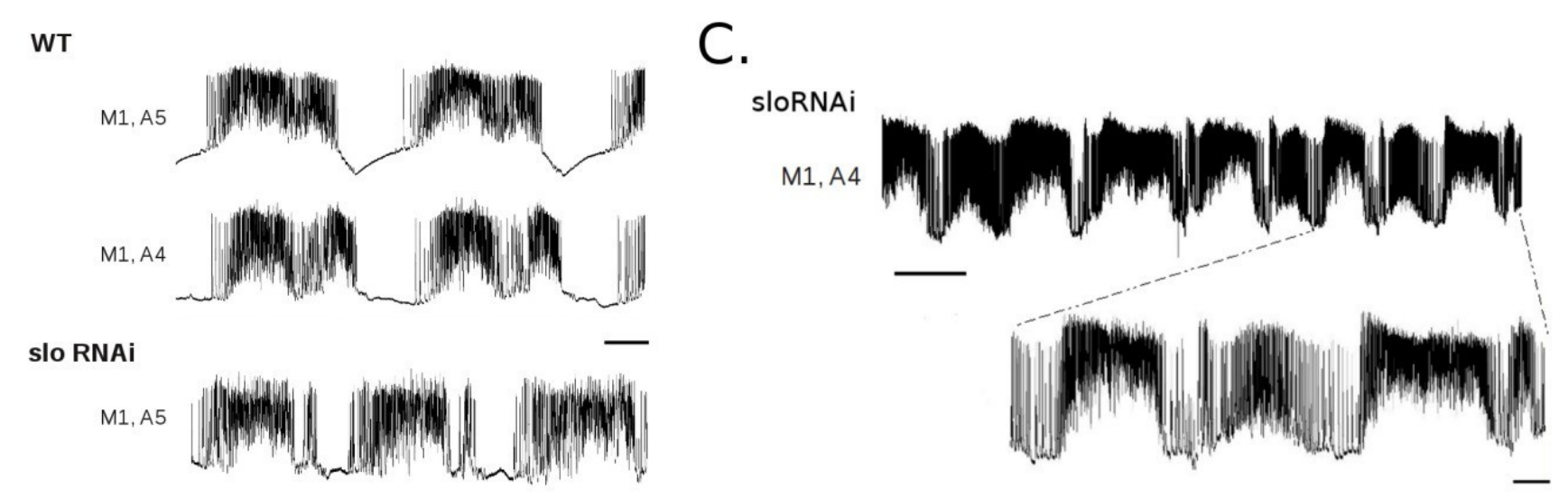

M1, A4

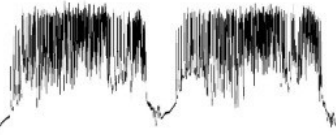


Figure 5

Quanti
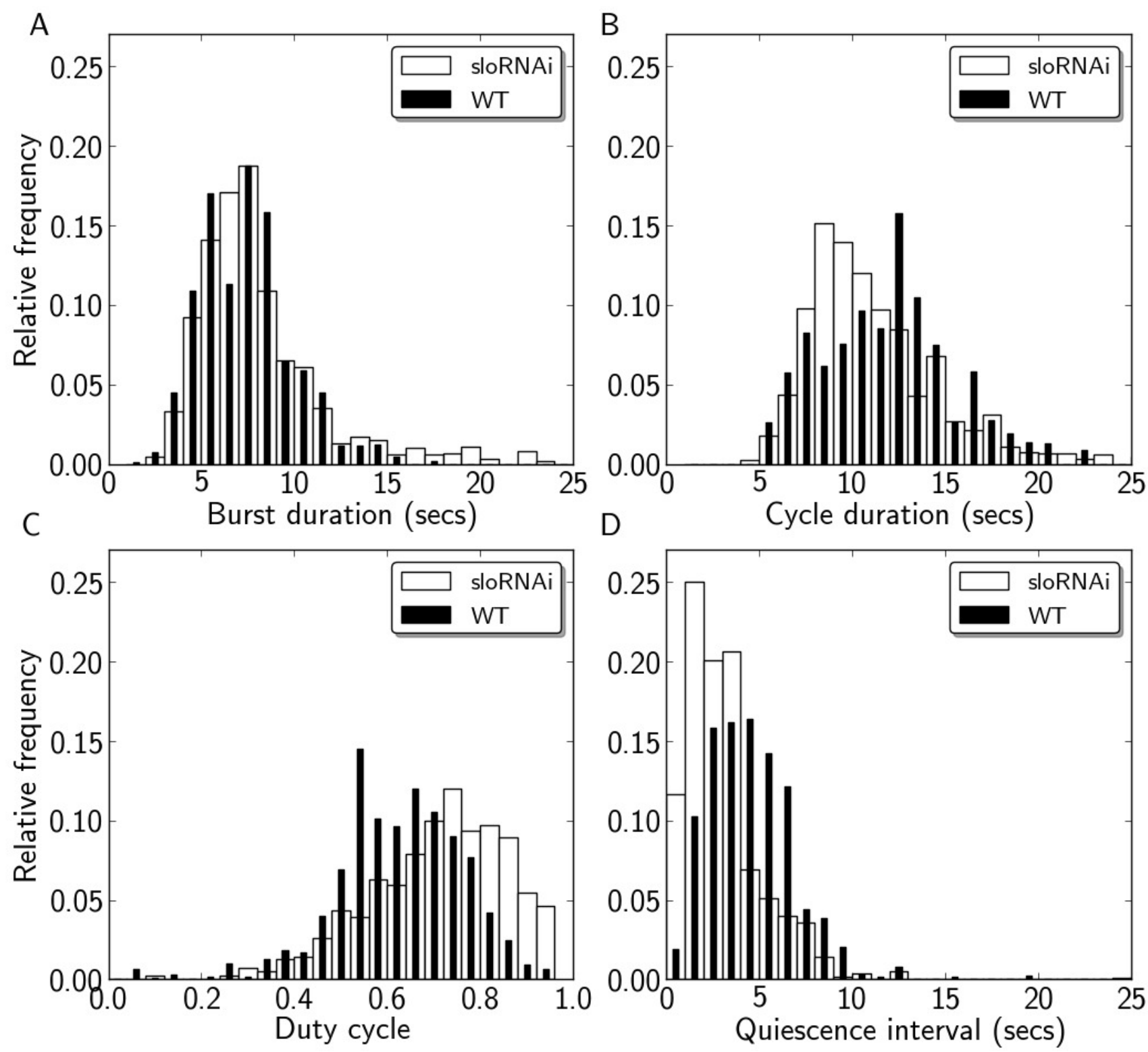